\title{
Research on the Characteristics of Folk Sports Culture Based on SWOT Method and Structure Equation
}

\author{
Cuixia $\mathrm{Yi}^{1, \mathrm{a}}$, Tao Yang $^{2,3}$ \\ ${ }^{1}$ School of Physical Education,Shaanxi Normal University,Xi'an, China \\ ${ }^{2}$ Shanghai University of Sport,Shanghai, China \\ ${ }^{3}$ Xi'an Physical Education University,Xi'an, China \\ ayi_cuixia@126.com
}

Keywords: SWOT method; structural equation; leverage effect; vulnerability formulas; T-algorithm

\begin{abstract}
In recent years, domestic folk sports research has became the one of the hottest topics in our country. Folk sports, just as the name implies, which is created by the masses, inherited by the people, apparently it's a traditional sports cultural movement in People's Daily life. On the one hand, it is a kind of sports, but on the other hand, it is also a kind of culture. At present research on the characteristics of domestic folk sports culture in our country is still staying on the surface of an overview of words, the depth of the characteristics research is just a superficial one. This paper adopted the SWOT analysis method and structural equation to study the local folk sports culture, attempted to have a vivid description in the form of change in depth. Then make sure people can have a transparent understanding of the folk sports culture. At the same time encouraged people pay more attention on the folk sports culture in the information age. In order to solve inheritance problem and domestic folk sports culture develop problem in the perennial history of the domestic folk sports culture ,it also improve the domestic people's sports culture quality, and contribute to showing the world with splendid Chinese national characteristics of folk sports culture.
\end{abstract}

\section{Introduction}

From the words of folk sports culture ,we can see the three key pionts of folk sports culture, namely folk, sports and culture[1]. This paper try proceeding with the three aspects of the Chinese nation so that we can have a better understanding on the folk sports culture internal and external characteristics.

The internal characteristics are mainly including the characteristics of sports competitive, entertainment characteristics, and so on, the external characteristics are mainly consist of historical characteristics and regional characteristics, and so on[2].In this paper,we have used the SWOT analysis method to study the characteristics of folk sports culture, to pursue the folk sports culture characteristics can be clearly showed to the world, which also promote the traditional culture spreading of folk sports culture. In the paper, first of all, we have a certain description of the folk sports culture concept and its classification, the present situation, development trends and restrict folk sports culture. Then we also describe the key part domestic folk sports cultural history, so that we can realize a clearly contrast between the modern folk sports culture and history of folk sports culture[3]. Finally, we began to use SWOT analysis to have a comprehensive study of the characteristics of folk sports culture. The paper prepared to adopt the above structure complete the research of folk sports culture, and provided certain reference for the future study about regional qualitative folk sports culture.

\section{The SWOT analysis theory of folk sport culture}

A. The brief introduction of SWOT analysis theory

As a kind of analysis theory ,SWOT has brought up by San Francisco university in the late 1960s, which has widely used in the analysis of the reality. Because of the objectivity and accuracy of it, so its utilization rate are more higher than other analysis in the present analysis method. SWOT 
consist of Strengths, Weaknesses, Opportunities, Threats four parts (as shown in Figure 1). It has analysed the strengths, weaknesses, opportunities and threats the four aspects of one thing, then through the assessment can we get the conclusion.

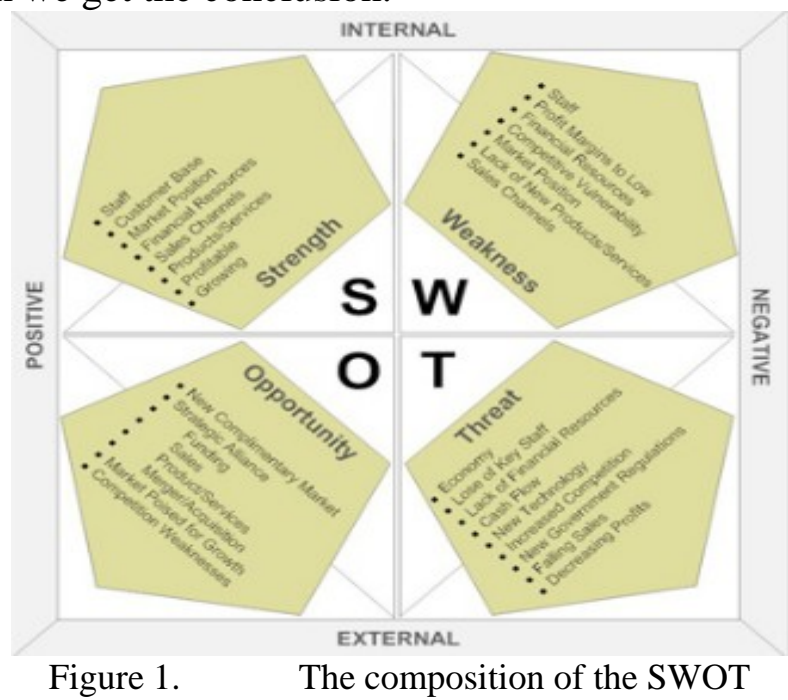

B. The SWOT analysis of folk sport culture

1) The advantage of folk sports culture (S)

Folk sports culture is one part of the Chinese traditional culture, because of its long history, makes it has more advantages in resources. Now like the dragon, the dragon boat and so on traditional folk sports,the folk sports also have been added to the Chinese intangible cultural heritageseries[4]. At the same time domestic folk sports culture also have its industrial advantage in domestic, for folk sports culture in domestic has been formed it tourism attraction in some place, because the culture has contacted huge number of crowd, which makes its spreading also have some advantages to certain degree.

2) The disadvantages of folksports cultural (W)

Due to so many domestic folk sports are presence, which makes folk sports cultural resources became very huge, and only a small part of it received a very good communication and use[5]. At the same time as our country began to rise the attention of the folk sports culture almost in recent years, so the protection planning for the folk sports culture is a little late, the local government executive power is weak to the above policy, if the executive power is not improved, which will lead to many folk sports culture lost or not good inheritance. Finally the professionals for folk sports in our countyr are extreme scarcity, the seriously problem will directly lead to a lot of folk sports culture can not have very good publicity and promotion, the spread of folk sports culture in domestic has an obvious optional which just as in a state of disunity.

3) The opportunities of folk sports culture (O)

In recent years, government began to pay more attention on cultural construction, which makes the folk sports culture in China has been attached great attemtion to the superior department and the protection of related folk sports culture has also put on the agenda, which provides a rare opportunity for protection of folk sports culture. At the same time due to the rapid development of domestic tourism, the diversity of tourism demand is gradually increasing, and folk sports culture as one of the characteristics for a local tourism make folk sports have a very good based on demand.

4) The threats of folk sports culture (T)

With the development of economy, the acceleration of urbanization, urban culture has produced a serious threat to regional folk sports culture, and this threat is increasingly serious. At the same time in the environment of global integration, the culture is almost gradually to assimilate, domestic culture is gradually invading on the domestic culture, making the survival condition for folk sports culture bcome very serious[6]. Finally the spreading of numerous folk sports culture exist certain competition in the domestic, because the competition has became intensification, which made part of folk sports culture spreading and inheriting appeared some problems. Review the three points, and it is also the major threats of the folk sports culture, according to these threats, we must put forward 
some solutions as soon as possible, so that the folk sports culture can received a very good protection, then make the inheritance and development more smooth .

After we have an fundamental understand on the folk sports culture SWOT problem, we are ready to use the SWOT analysis model method to study the characteristics of the domestic folk sports.

First of all, we should use this method of leverage effect $(G)$, its formula is as follows:

$\mathrm{G}=\mathrm{S}+\mathrm{O}$

In the use of the lever benefit formula, we can understand only grasp its advantages and opportunities, then the folk sports culture can make the folk sports culture get better development.

Secondly, the use of inhibitory (Y) method, its formula is as follows:

$\mathrm{Y}=\mathrm{O}+\mathrm{W}$

In the use of the above inhibitory formula, as the folk sports cultural opportunities and folk sports culture advantage for do not fitted, the advantage to expand of folk sports culture would be hard to get the play. In this case, the folk sports culture must promote the transformation of disadvantages into advantages direction, so as to it will better fit for the external opportunity.

After that, we use the folk sports culture vulnerability (C) method, the formula of vulnerability is as follows:

\section{$\mathrm{C}=\mathrm{S}+\mathrm{W}$}

In the use of the vulnerability formula,as the environment of domestic folk have became a threat for sports culture, the advantages can not give a full play.In his kind of circumstance, folk sports culture must overcome the threats, to make sure the folk sports culture can play the biggest advantage.

Finally, we use the folk sports culture problem solving (Q) method, using the formula of problem is as follows:

\section{$\mathrm{Q}=\mathrm{W}+\mathrm{T}$}

In the use of the above folk problem solving formula of sports culture, as the folk sports culture internal weaknesses and external threat meet, sports folk culture is facing the severe situation, if it not handled properly, some folk sports culture life and death may threaten.

In the multianalysis of domestic folk sports cultural characteristics through the use of above SWOT model,makes us have more clear understanding to the development direction of domestic folk sports culture in the future, and the problem it should be solved in the future.

\section{Analysis of domestic folk sports culture characteristic based on the structural equation model}

A. Model assumption

We can establish the model assumption as follows:

(1) Assuming the existence of index $a_{i}, b_{j}(i=1,2, \cdots, n ; j=1,2, \cdots, m)$, corresponding to latent variable factor load is not 0 , and sport culture endogenous variable path is determined in accordance with relevant theory;

(2) Between error term $u_{i}$ and sports culture exogenous latent variables $v_{j}(i, j=1,2, \cdots, n)$ are no correlation.

B. Establishing domestic folk sports culture structure equation model path graph

Combined with the folk sports culture research purposes, to establish the effect cultural characteristic and the cultural value parameter factor model, and to estimate associated factor parameter, correction, determine structure, setting up structural equation model as shown in Figure 3[8-9].

In Figure 3, it can be shown that the form of domestic folk sports culture structure model parameters is set for[7]: 


$$
\left(\begin{array}{l}
a_{1} \\
a_{2} \\
\vdots \\
\vdots \\
a_{11}
\end{array}\right)=\left(\begin{array}{lll}
\alpha_{11} & 0 & 0 \\
\alpha_{21} & 0 & 0 \\
\alpha_{31} & 0 & 0 \\
\alpha_{41} & 0 & 0 \\
\alpha_{51} & 0 & 0 \\
0 & \alpha_{62} & 0 \\
0 & \alpha_{72} & 0 \\
0 & \alpha_{82} & 0 \\
0 & 0 & \alpha_{93} \\
0 & 0 & \alpha_{10,3} \\
0 & 0 & \alpha_{11,3}
\end{array}\right)\left(\begin{array}{l}
v_{1} \\
v_{2} \\
v_{3}
\end{array}\right)+\left(\begin{array}{l}
\mu_{1} \\
\mu_{2} \\
\vdots \\
\vdots \\
\mu_{11}
\end{array}\right) \quad(2)\left(\begin{array}{l}
b_{1} \\
b_{2}
\end{array}\right)=\left(\begin{array}{ll}
\beta_{11} & 0 \\
0 & \beta_{22}
\end{array}\right)\left(\begin{array}{l}
\mu_{1} \\
\mu_{2}
\end{array}\right)+\left(\begin{array}{l}
v_{1} \\
v_{2}
\end{array}\right)
$$

Therefore, domestic folk sport culture influence's endogenous latent variables are respectively $u_{1}$ and $u_{2}$; the parameter value of $\beta_{11}$ and $\beta_{22}$ are both equal to 1 .

C. Identification of domestic folk sports culture structure model

Generally, using the ${ }^{t-}$ rule to carry out judgment model, common having $(n+m)$ variables in the structural equation model. Therefore, domestic folk sport culture structure model can identify the necessary conditions for[8]

$$
t \leq(n+m)(n+m+1) / 2
$$

The the equation model of domestic folk sport culture uses the standard parameter to carry out estimation results, which mainly consist of two steps: first establishing cultural structure model to validy factor, and to determine model's latent variable structure; according to Figure 3 model path, to carry out program operation, deleting error path and repeating operation, to display factor load, i.e. $a=90 \%$, which can get the equations estimating models of the domestic folk sport culture, that is[9] :

$$
\begin{aligned}
& (1)\left(\begin{array}{l}
a_{1} \\
a_{2} \\
\vdots \\
\vdots \\
a_{11}
\end{array}\right)=\left(\begin{array}{lll}
0.414 & 0 & 0 \\
0.732 & 0 & 0 \\
0.758 & 0 & 0 \\
0.860 & 0 & 0 \\
0.663 & 0 & 0 \\
0 & 0.539 & 0 \\
0 & 0.649 & 0 \\
0 & 0.634 & 0 \\
0 & 0 & 0.920 \\
0 & 0 & 0.447 \\
0 & 0 & 0.234
\end{array}\right)\left(\begin{array}{l}
v_{1} \\
v_{2} \\
v_{3}
\end{array}\right)+\left(\begin{array}{l}
\mu_{1} \\
\mu_{2} \\
\vdots \\
\vdots \\
\mu_{11}
\end{array}\right) \\
& \text { (2) }\left(\begin{array}{l}
b_{1} \\
b_{2}
\end{array}\right)=\left(\begin{array}{lr}
0.967 & 0 \\
0 & 0.876
\end{array}\right)\left(\begin{array}{l}
\eta_{1} \\
\eta_{2}
\end{array}\right)+\left(\begin{array}{l}
\varepsilon_{1} \\
\varepsilon_{2}
\end{array}\right) \\
& \text { (3) }\left(\begin{array}{l}
\eta_{1} \\
\eta_{2}
\end{array}\right)=\left(\begin{array}{ll}
0 & 0 \\
0.244 & 0
\end{array}\right)\left(\begin{array}{l}
\eta_{1} \\
\eta_{2}
\end{array}\right)+\left(\begin{array}{ccc}
0.133 & 0.152 & 0.165 \\
0.141 & 0 & 0
\end{array}\right)\left(\begin{array}{l}
v_{1} \\
v_{2} \\
v_{3}
\end{array}\right)+\left(\begin{array}{l}
\gamma_{1} \\
\gamma_{2}
\end{array}\right)
\end{aligned}
$$

In model equation, the output results have no error apparent parameter estimation, it describes that the folk sport culture can use the model to fit the original sport culture data, which is more appropriate.

\section{Conclusion}

The paper uses SWOT method and to have a detailed description for domestic folk sports culture characteristics, which make people have an more clearly understand on the current domestic folk 
sports culture development path and how to solve the development problem of folk sports culture. To understand these problems later, try hard to improve the current situation of folk sports culture, get better protection for the current folk sports culture, make good use of the domestic folk sports culture, and promote local economic and cultural development, and strive to be the Chinese nation traditional culture to transmit down and carry forward.

\section{References}

[1] Liu Minhang.The research of folk sports function classification and features. Joural of Shandong sports institute,2012(2):48-51.

[2] Tu Chuanfei, Yu Wanyu, Chao Qunying. The research of folk sports characteristics . Journal of wuhan institute of physical education. 2010(9):67-69.

[3] Tu Chuanfei. The discuss for folk sports, traditional sports, folk sports, national sports concept.Wuhan sports college,2009(8):34-37.

[4] LiuJing, Yu Hanqiao. From the cultural structure to see the modernization development of national tradition sports the dragon and lion dance movement. Journal of Beijing sports university,2011(4):78-83.

[5] Li li. Restriction factors on the development of folk sports culture . Management aspect,2012(7):103-107

[6] Dai Weihong, Xun Hongfeng. Folk sports research prospecting and looking back.Journal of sports culture guide,2010(10):98-101

[7] Sheng Changfan, Deng Panhua. Our country folk sports characteristics and development research . Journal of southwest normal university (natural science edition),2009(12):34-37.

[8] Li Hongmei, Zheng Guorong, Wan Qianhua. Theory of folk sports modernization development . Journal of shenyang institute of physical education,2012(11):13-15.

[9] Gao Songshan, Yun Linsen, Zhang Wenpu.The development and utilization of HeLuo folk folk sports culture . Introduction to sports culture,2012(3):67-69. 